\title{
Acquisition of the same/different concept by an African Grey parrot (Psittacus erithacus): Learning with respect to categories of color, shape, and material
}

\author{
IRENE M. PEPPERBERG \\ Northwestern University, Evanston, Illinois
}

\begin{abstract}
An African Grey parrot, previously taught to use vocal English labels to discriminate more than 80 different objects and to respond to questions concerning categorical concepts of color and shape, was trained and tested on relational concepts of same and different. The subject, Alex, replied with the correct English categorical label ("color," "shape," or "mah-mah" [matter]) when asked "What's same?" or "What's different?" about pairs of objects that varied with respect to any combination of attributes. His accuracy was $69.7 \%-76.6 \%$ for pairs of familiar objects not used in training and $\mathbf{8 2 . 3 \%}-\mathbf{8 5 \%}$ for pairs involving objects whose combinations of colors, shapes, and materials were unfamiliar. Additional trials demonstrated that his responses were based upon the question being posed as well as the attributes of the objects. These findings are discussed in terms of his comprehension of the categories of color, shape, and material and as evidence of his competence in an exceptional (non-species-specific) communication code.
\end{abstract}

Recent studies (Pepperberg, 1987a, 1987b) have shown that at least one avian subject, an African Grey parrot (Psittacus erithacus), can exhibit capacities once thought to belong exclusively to humans and, possibly, certain nonhuman primates (see Premack, 1978). This parrot has learned to use English vocalizations to identify, request, refuse, or comment upon more than $\mathbf{8 0}$ different objects of various colors, shapes, and materials (Pepperberg, $1979,1981,1987 \mathrm{~b}$ ). He has demonstrated a rudimentary capacity for categorization (Pepperberg, 1983a), can identify quantity for collections of up to 6 objects (Pepperberg, 1987a), and has functional use of phrases such as "come here," "no," and "I want X" and "Wanna go $Y$," where $X$ and $Y$ are appropriate objects or location labels (Pepperberg, 1981, 1987b, in press).

The above findings, however, do little to counter arguments for species-specific differences (e.g., speciesbased hierarchies) in the ability of nonhumans to comprehend and use abstract symbolic relationships (Premack, 1978, 1983; Rumbaugh \& Pate, 1984; Savage-Rumbaugh, Sevcik, Rumbaugh, \& Rubert, 1985). Although biological constraints are not generally thought to limit the abil-

This research was supported by National Science Foundation Grant BNS 84-14483 and by the Harry Frank Guggenheim Foundation. I thank Katherine Davidson, Denise Dickson, Dawn Matias, Mary Sandhage, Debra Sauriol, Leah Schimmel, Florence Kozak, Stephanie Moore, Denise Neapolitan, Laura O'Brien, Daniel Rutledge, and Katharine Spangler for their assistance as secondary trainers, and Malcolm Dow for suggestions on the statistics. Thomas Zentall, Anthony Wright, and unknown referees provided valuable comments on an earlier version of the manuscript. Portions of this paper were presented at the 1986 International Ornithological Congress, Ottawa, Canada. Address correspondence to Irene M. Pepperberg, Department of Anthropology, Northwestern University, 1810 Hinman Avenue, Evanston, IL 60201. ity of animals to master nonrelational concepts, several researchers suggest that existing data on relational concepts reflect qualitative as well as quantitative species differences. Other researchers argue that the demonstrated differences can often be attributed to experimental design rather than to underlying animal cognitive capacities (e.g., Kamil, 1984; Menzel \& Juno, 1982, 1985; Pepperberg, 1981, 1986; cf. review in MacPhail, 1985), but the suggestion remains that there are certain tasks that cannot be mastered by nonprimate subjects.

One cognitive capacity in particular, comprehension of same/different, has been singled out as a concept not typically attributable to nonprimates (Premack, 1978, 1983). There is significant debate in the literature concerning exactly what has been demonstrated in the various animal studies purporting to examine same/different (e.g., Edwards, Jagielo, \& Zentall, 1983; Premack, 1983, and commentaries therein). For example, some pigeons trained on match-to-sample or oddity-from-sample tasks actually learned little about the nonmatching alternative; that is, they acquired a concept of same but not one of different (see discussions in Edwards et al., 1983; Zentall, Edwards, Moore, \& Hogan, 1981). Also, according to Premack, comprehension of same/different is not the same as being able to respond to match-to-sample and oddity-from-sample, but rather involves the ability to use arbitrary symbols to represent the relationships of sameness and difference between sets of objects. That is, for generalized match-to-sample or oddity-from-sample, the subject demonstrates its understanding of the concept simply by showing a savings in the number of trials needed to respond to $B$ and $B$ as a match after learning to respond to $A$ and $A$ as a match (and, likewise, by showing a sav- 
ings in trials involving $C$ and $D$ after learning to respond to $A$ and $B$ as nonmatching). But, according to Premack, demonstrating comprehension of same requires a subject to recognize not only that two independent objects-call them A1 and A2-are blue, but that only a single attribute- the category color-is shared. The subject must also recognize that this attribute, or sameness, can be immediately extrapolated and symbolically represented not only for two other blue items, but for two novel, independent green items-B1 and B2-that have nothing in common with the original set of As. Likewise, the subject would have to demonstrate a concept of difference that could also be extrapolated to two entirely novel objects. Premack $(1978,1983)$ proposed that such abilities were likely to be limited to primates and, because of the requirement for symbolization, were most readily demonstrated by nonhuman primates that had undergone some form of language training.

Recently, Zentall and his colleagues (Edwards et al., 1983; Zentall et al., 1981; Zentall, Hogan, \& Edwards, 1984) have demonstrated that pigeons (Columba livia) can show a significant degree of same/different concept transfer, including use of symbols to represent same versus different. Although the pigeons' performances were influenced by stimulus-specific associations, the birds did respond symbolically and needed fewer sessions to respond correctly to novel instances of same and different when the task remained the same than when it did not. Wright and his colleagues (Santiago \& Wright, 1984; Wright, Santiago, \& Sands, 1984; Wright, Santiago, Urcuioli, \& Sands, 1984) have also shown that both monkeys (Macaca mulatta) and pigeons can use two-choice symbolic responses to demonstrate same/different concept learning. The pigeons, although scoring above chance, showed a much lower level of transfer to novel items than did the monkeys. These experiments, although suggestive, did not demonstrate that a bird could use symbols for "same" and "different" in a manner fully comparable to that of language-trained chimpanzees or humans, or even appropriately trained monkeys.

Few other studies have investigated concepts of same/different in avian subjects, even though natural behaviors of individual recognition and vocal dueling and song matching (e.g., Beecher, Stoddard, \& Loesche, 1985; Falls, 1985; Falls, Krebs, \& McGregor, 1982; Kroodsma, 1979) would make categorization based on similarity or difference seem an adaptive trait. Starlings (Sturnus vulgaris), cowbirds (Molothrus ater), and mockingbirds (Mimus polyglottos) appear capable of classifying novel series of tones as ascending or descendingi.e., "same" or "different" from ascending or descending reference series-but only for sequences that fall within the range of frequencies used in training (Hulse \& Cynx, 1985). In laboratory studies by Park and Dooling (1985) on the ability of budgerigars (Melopsittacus undulatus) to discriminate similarities and differences in calls of canaries (Serinus canarius), the budgerigars appeared to learn the unique characteristics of each in- dividual canary call. Similar results were found by P. K. Stoddard and M. D. Beecher (personal communication, May 1986) in studies on song discrimination with cliff swallows (Hirundo pyrrhonota) and barn swallows (Hirundo rustica). Related studies by Shy, McGregor, and Krebs (1986) on great tits (Parus major) have demonstrated the ability of these birds to recognize test songs as similar to or different from one particular training song (comparable to visual categorization by pigeons; e.g., Herrnstein, 1984). None of these studies, however, has shown actual labeling of the relation of sameness or difference as, for example, demonstrated by transfer to entirely different exemplars (e.g., calls or songs of different species).

The present study was therefore undertaken to see if an avian subject, the aforementioned African Grey parrot, could use vocal labels to demonstrate symbolic comprehension of the concepts of same and different.

\section{METHOD}

\section{Subject}

The subject, an African Grey parrot named Alex, had been the focus of a study on interspecies communication and cognitive abilities since June 1977. He was allowed free access (contingent upon his vocal requests; e.g., "Wanna go gym") to all parts of the laboratory for the $8 \mathrm{~h}$ /day that trainers were present; hence, trials occurred at various locations. During sleeping hours, however, he was confined to a wire cage $(\sim 62 \times 62 \times 73 \mathrm{~cm})$. Water and a standard seed mix for psittacids (sunflower seeds, dried corn, kibble, oats, safflower, etc.) were available continuously; fresh fruits, vegetables, specialty nuts (cashews, almonds, pecans, walnuts) and toys (keys, pieces of wood, paper, rawhide, etc.) were provided at the bird's vocal request (e.g., "I want cork.")

\section{Experimental Design}

For the reasons discussed above, the task designed for the present subject would have to be functionally equivalent to that used with Premack's $(1976,1983)$ chimpanzees: The task would have to ensure that (1) the symbolic concepts tested would be more abstract than those examined in standard conditional discrimination paradigms; (2) the subject would be given explicit, equal training on concepts of both same and different; (3) the findings could not be dismissed as stimulus-specific associations; and (4) first-trial transfer test results could be examined for their significance.

To take into account these constraints and the history of the experimental subject with respect to use of vocal labels, the following task was designed. Alex was to be presented with two objects that could differ with respect to three categories: color, shape, or material (e.g., a yellow rawhide pentagon and a gray wooden pentagon; a green wooden triangle and a blue wooden triangle). He would then be queried "What's same?" or "What's different?" The correct response would be the label of the appropriate category, not the specific color, shape, or material marker, that represented the correct response (e.g., "color," not "yellow'). Therefore, to be correct, Alex would have to (1) attend to multiple aspects of two different objects; (2) determine, from a vocal question, whether the response was to be on the basis of sameness or difference; (3) determine, from the exemplars, what was same or different (e.g., were they both blue, or triangular, or made of wood?); and then (4) produce, vocally, the label for this particular category. Thus, the task required, at some level, that Alex perform a feature analysis of the two objects: The responses could not be made on the basis of total physical similarity or difference (see Premack, 1983). 
For comparison, remember that most research on the same/different concept in animals uses (1) a two-choice design whereby the subject merely indicates whether pairs do or do not match, (2) a topographically similar (and thus possibly easier to acquire) response for both answers (e.g., leverpressing or keypecking; see Michael, Whitely, \& Hesse, 1983), and (3) same pairs that are identical in all dimensions and different pairs that are different with respect to most, if not all, dimensions. This would be equivalent to asking Alex to view two objects and merely respond "same" or "different," the latter response applying to anything that was different. But Alex was expected to respond with the vocal label of one out of three dimensions that was the same or different for each pair depending upon the question he was asked, which was a considerably more difficult task. Note, too, that McClure and Helland (1979) have shown that even chimpanzees will not respond "different" as reliably for pairs of objects differing on only one of three dimensions as for pairs differing on two dimensions.

At the time this experiment began, Alex could already produce vocal (English) labels for five colors (green, rose [red], blue, yellow, and gray), several shapes (2-, 3-, 4-, and 5-corner for, respectively, football-shaped, triangular, square, and pentagonal forms), four materials (paper, wood, hide [rawhide], and cork) and various metallic items (such as key, chain, or grate). He had also shown a limited comprehension of abstract categories, in that he could respond to vocal questions of "What color?" or "What shape?" with the correct label for the targeted attribute (e.g., "green wood" or "5-corner hide") for objects that simultaneously incorporated even novel combinations of both variables (green wooden "footballs," yellow rawhide pentagons; Pepperberg, 1983a). During the course of the experiment, he acquired labels for orange and purple and six-cornered shapes. This meant that he had a considerable number of possible exemplars for the problems (see Premack, 1976, p. 132), and that labels for all of these items, as well as labels for foods, locations, and quantity, were always available in the repertoire as possible answers. Consequently, Alex was not limited merely to choosing between symbols representing same or different, or to choosing physically between only two objects that were similar to or different from a sample.

Alex's responses on tests were unlikely to be made on the basis of absolute physical properties or by learning the answer to a given pair, as the number of possible permutations of question topic, correct response, and combination of exemplar attributes was very large. ${ }^{1}$ Moreover, because Alex's response would be a category label rather than a specific object or attribute label, we could also employ totally novel objects whose labels were unknown. Thus, the parrot would have to be able to transfer between like and unlike pairs of colors, like and unlike pairs of shapes, and like and unlike pairs of materials, all of which would vary from the training exemplars; that is, he would have to demonstrate transfer among stimulus domains as well as among various instances of each domain (see Premack, 1976, pp. 354-355, for the importance of such transfers in determining that the behavior is not just stimulus generalization). In addition, we planned to conduct probes to determine whether Alex was responding to the content of the questions (i.e., differentially processing “What's same?" vs. "What's different?"), and not just responding to variations in the physical properties of the exemplars.

In sum, after training, Alex was to be given a series of questions involving, in random order, pairs of objects that were familiar to him but were not used in training, pairs in which one or both exemplars were totally novel objects, and probes to examine if he was indeed processing the content of the questions (see below).

The results of these experiments were intended not only to provide information on the parrot's concepts of same and different, but also to provide additional evidence for comprehension of concepts of categories; that is, the ability to recognize that two novel objects (e.g., pink and brown paper triangles) differed with respect to the category "color" even though the colors were untrained and the specific combinations of color, shape, and material for each exemplar, as well as for the pair, had never before been seen by Alex on a test. A correct response would suggest that the parrot was not responding to specific instances of color, shape, and material, but rather on the basis of the categorical concepts.

\section{Training Procedures}

General. The general training procedures for label acquisition and the rationale for their use have been described in detail elsewhere (Pepperberg, 1981); a review will be given here.

The primary technique, called the model/rival, or $\mathbf{M} / \mathbf{R}$, approach, has humans demonstrate to the parrot the types of interactive responses desired. This procedure is based on a protocol developed by Todt (1975) for examining vocal learning in Grey parrots, but also derives much from the social modeling theories of Mowrer (1960) and Bandura (1971). One human acts as the trainer of a second human by presenting objects, asking questions about these objects, giving praise and reward for correct answers, and showing disapproval of incorrect answers (errors similar to those being made by the bird at the time; e.g., "wood" for "green wood"). The second human acts both as a model for the bird's responses and as a rival for the trainer's attention. Roles of model/rival and trainer are frequently reversed, and the parrot is given the opportunity to participate in these vocal exchanges.

During training on label acquisition at the start of the project (e.g., Pepperberg, 1981), each correct identification was rewarded with the object itself, a system that permits the closest possible correlations between the object or category and the label to be learned. This protocol was crucial for initially training labeling ability (see discussion in Pepperberg, 1981, 1983a). For the present study, the correct response was rewarded with acquisition of both objects. To motivate Alex to work with objects in which he had little interest, we also modified the procedure to allow him to request alternative objects as his reward (see Pepperberg, 1987a, 1987b): He had already been trained to preface requests with the phrase "I want ..." and to employ object labels alone (e.g., "blue wood") for identifications (Pepperberg, in press). A previous study (Pepperberg, 1987b) showed that Alex usually ( $\sim 75 \%$ of the time) did indeed want the objects he requested. He would eat the walnut or use the key to scratch himself or the cork to clean his beak, and he would refuse substitute items, usually with the vocalization "no" and a repetition of the original request. Thus, during work on sameldifferent, an interruptive vocalization such as "cork" was considered an error, whereas "I want cork" was taken as a valid request rather than a mistake. However, only after correct responses to the targeted objects were his requests for an alternative accommodated.

Same/different. During training on same/different, Alex observed the following: A trainer would hold two objects in front of the model, and ask either "What's same?" (e.g., for a red wooden triangle and a green rawhide triangle) or "What's different?" (e.g., for a red wooden square and a blue wooden square). Both questions and various object pairs were interspersed in a single session, although we specifically limited training to a subset of already familiar exemplars-objects that were red, green, or blue; triangular or square; rawhide or wood. The model would respond with the label for the correct category and be rewarded with the objects (or the right to choose a reward), or err and be scolded. If an error was made, the objects would momentarily be removed from view (a "time-out"), then re-presented and the question repeated. Roles of trainer and model/rival would then be reversed.

Initial training contrasted the categories of color and shape because Alex had already demonstrated some comprehension of these categories by correctly responding to questions of "What color?" versus "What shape?" for objects that had both color and shape, and he occasionally produced those phrases in the presence of various objects ${ }^{2}$ (Pepperberg, 1983a). Alex was trained on the third 
category label, "mah-mah" (matter), after he began to use the labels "color" and "shape" separately from the phrases "What color?" or "What shape?" Training sessions occurred 2-4 times/week and lasted $5 \mathrm{~min}-1 \mathrm{~h}$.

In addition, we were concurrently training or testing Alex on number concepts (Pepperberg, 1987a), new labels (Pepperberg, 1987b), photograph recognition, and awareness of object permanence (Pepperberg \& Kozak, 1986). Concurrent work on a variety of tasks is an important experimental protocol for this project: Alex becomes restless during sessions devoted to a single task. He will cease to work, begin to preen, or interrupt with many successive requests for other items ("I want $X$ ") or changes of location ("Wanna go Y'; see Pepperberg, 1983a, 1987a). Similar "'boredom”' behavior has been observed in meerkats (Suricata suricatta, Moran, Joch, \& Sorenson, 1983), raccoons (Procyon lotor, Davis, 1984), chimpanzees (Pan troglodytes, Putney, 1985), and Long-Evans hooded rats (Davis \& Bradford, 1986).

\section{Criterion Prior to Testing}

Normally, the criterion as to when a newly acquired, targeted skill (e.g., the ability to label an object) can formally be tested is based on the clarity of Alex's speech ("production"), and not on the accuracy of his performance of the task in question ("comprehension'; see discussion in Pepperberg, 1981). This criterion separates the effect of our procedures on the subject's physical ability to emit a label from the effect of our procedures on his ability to make a correlation between the label and its referent. Only when the former skill is considered satisfactory do we deem the latter ready for testing (Pepperberg, 1981, 1983a) ${ }^{3}$ In this experiment, because Alex could already produce the labels "color" and "shape," we delayed testing until the label "mah-mah" (matter) had been acquired.

\section{Test Procedures}

Specifics of the protocol used in all tests were presented in Pepperberg (1981). A summary follows: To lessen the possibility of trainer-induced cuing (Pepperberg, 1981), trials were conducted by secondary trainers who never trained Alex on sameldifferent. We examined Alex's knowledge of same/different by including, on each object identification test or in the midst of a training session on, for example, numerical concepts, only one (or, rarely, two) trials of "What's same?" or "What's different?" Tests were constructed as follows: On a previous day, all of the possible objects to be tested were listed by the principal trainer. A student not involved in testing would then choose the question, form the pairs for same/different, and randomly order all the questions. ${ }^{4}$ Questions on same/different were asked on average one to four times per week, and neither Alex nor the principal trainer could predict which questions on which topic would appear on a given day. Testing on sameldifferent occurred between February 1984 and April 1986.

A secondary trainer would present to the bird, in a variable but previously determined order, the objects to be identified. The parrot was thus shown an exemplar or number of exemplars, asked "What's this?" "What color?" "What shape?" "How many?" "'What's same?" or "What's different?" and was required to formulate a vocal English response from the 80 possible vocalizations in his repertoire (Pepperberg, 1987b). "What shape?" and "What color?" were used during data collection of the type described in Pepperberg (1983a) for categories, or as a second question when Alex responded to "What's this?" by identifying correctly only the material of a colored or shaped object. (Such "generic" answers were considered errors; Pepperberg, 1981). "How many?" was similarly employed if he labeled only the material of a collection of objects during concurrent testing on numerical concepts (see Pepperberg, 1987a).

The principal trainer was present, but sat in a corner of the room with her back to the parrot, did not look at the bird during presen- tation of the test object(s), and therefore did not know what was being presented. The principal trainer repeated out loud what she heard the bird say. If that was indeed the correct response (e.g., the appropriate category label), the parrot was rewarded by praise and the object(s). There were then no additional presentations of the same material during that test; that is, there was only a single, "first-trial" response. If the identification was incorrect or indistinct, the examiner removed the object(s), turned his/her head (a momentary time-out), and emphatically said "No!" The examiner then implemented a correction procedure in that the misnamed object or collection was then immediately and repeatedly presented until a correct identification was made; errors were recorded. ${ }^{5}$ The parrot thus found-and appeared to learn-that an incorrect identification (e.g., substitution of the name of a more desired object for the one presented) was fruitless; instead, a quick, correct identification allowed him to request the preferred item. Because immediate and repeated presentation of an object or collection of objects during a test occurred only when the response to the initial presentation was incorrect, the testing protocol penalized use of a "winstay" strategy: incorrect repetition of a previously correct response (e.g., the name of the previous exemplar) elicited no reward. The testing procedure thus provided a definite contrast to training protocols that rely on, and occasionally reinforce, repetitive behaviors. At all stages, the overall test score (results for "all trials") was obtained by dividing the total number of correct identifications (i.e., the predetermined number of objects or collections) by the total number of presentations required. First-trial results (percentage of first trials that were correct) are reported for comparison.

In addition to avoiding the boredom factor noted above, intermingling different types of questions on tests or during training on other topics prevented "expectation cuing"': in single-topic tests, contextual information (the homogeneous nature of questions that have a relatively restricted range of answers) could be responsible for a somewhat better performance than would otherwise be justified by a subject's actual knowledge of the topic. But Alex was never tested exclusively on same/different questions and, more importantly, was never tested successively in one session on similar questions ("'What's same?') or questions that would have one particular correct response (e.g., "color"). A question was repeated in a session only if his initial answer was perceived as incorrect (see above, Pepperberg, 1981). Thus, even though the range of correct responses to questions of "What's same?" or "What's different?" was limited to three choices ("color," "shape," or "matter"), in any session Alex also had to choose from among many possible responses to other questions such as "How many?" or "What color?' in order to be correct (Pepperberg, 1983a, 1987a).

\section{Tests on Familiar Objects}

These trials involved object pairs that were similar to, but never the same as, those used in training. These were chosen to avoid problems with fear of unfamiliar exemplars (Zentall et al., 1981; Zentall \& Hogan, 1974). These items combined one additional color, shape, or material available in the laboratory - that is, variously colored and shaped objects of wood and rawhide (e.g., 5-corner blue wood) and, later, variously shaped keys. These trials also included later presentations of objects that had previously been examined as "novel" exemplars on the transfer tests; in such cases, the pairings were such that either the question (same vs. different) or the appropriate response category (color, shape, or matter) was altered from the previous trial in which the object appeared. Thus, although individual objects were used in more than one trial, the pairings of objects were constructed so as to always be novel; a particular pair was re-presented only when Alex erred.

\section{Transfer Tests with Novel Objects}

Object pairs for the second set of transfer tests were interspersed randomly within the first set. In these tests, Alex was presented 
with pairs of objects that combined several attributes never used in training or previous tests on same/different (e.g., 5-corner white paper) or totally novel objects incorporating colors, shapes, or materials for which he might not even have labels (e.g., pink woolen pompom) ${ }^{6}$ In these pairs, at least one and often both objects were items that were thus totally unfamiliar to Alex. They could be made of colors or shapes that he had probably seen, such as white or round (e.g., on clothing or foods), but could not label; they could be objects, such as toy cars, with which he at the time had had no experience. The object pairs used as stimuli are listed in the Appendix; the pairs and the question are listed in the order in which they were presented, and Alex's responses, except for requests for other items ("I want $X$ "), are reported in the order in which they were produced.

Objects that were completely novel (e.g., toy cars) were shelved in Alex's view for several days prior to their use to avoid a possible fear response (see Zentall et al., 1981; Zentall \& Hogan, 1974), but were never the subject of training. These objects were handled by humans as part of laboratory cleaning, for example, but the colors, shapes, or materials of these items were never labeled.

\section{Probes}

One concern was that, in formulating his answers, Alex might not be attending to the questions, but merely be responding on the basis of the physical characteristics of the objects themselves. That is, by looking at the objects, he could have determined the one attribute that was same or different and simply responded on that basis. Thus, at random intervals, probes were administered in which Alex was asked questions for which either of two (of the three) category labels could be the correct response; that is, he would be shown a yellow and a blue wooden triangle and asked "What's same?" If he were ignoring the content of the question and answering on the basis of the attributes and his prior training, he would have responded with the one wrong answer; if he were answering the question posed, he would have two possible correct responses. Note, too, that having two possible correct answers provided additional protection against expectation cuing.

As usual, Alex's rewards for a correct response on any of these trials were the objects themselves or the opportunity to request another item.

\section{RESULTS}

\section{Training}

Training to acquire "color" and "shape" as labels separate from the questions "What color?" and "What shape?" (vocalizations acquired incidentally from their use by trainers in a different study, Pepperberg, 1983a) took 4 months; training to acquire "mah-mah," a totally novel vocalization, took 9 months. The length of time needed to train was not necessarily an indication of Alex's abilities; rather, it may have reflected the fact that we were concurrently training and testing various other tasks for the reasons described above. In addition, vocalizations that involve novel phonemes (sounds that do not occur in previously acquired labels) take considerably longer to train than those that are recombinations of familiar phonemes. Once motor control of syrinx, tongue, and beak exists for a set of sounds, these sounds are more easily produced and transferred to other labels (Pepperberg, 1983a).

The length of each session depended upon Alex's willingness to attend, and, because the amount of training re- quired for production of the appropriate category label did not necessarily correspond to that required for comprehension of the task, the number of trials needed for him to acquire the category labels was not judged to be an appropriate measure of his comprehension of the task. It is indeed possible that Alex had begun to acquire the sameldifferent concept before he could produce the required category labels: in the initial stages of training, he would often give the label of the particular instance of the category that was same (e.g., "yellow") or one of the two that was different (e.g., "3-corner").

\section{Tests on Familiar Objects}

Alex's score was $99 / 129=76.6 \%$ for all trials (first trials plus correction procedures), $69 / 99=69.7 \%$ on first-trial-only performance, $p<.0001$ on binomial test with a chance value of $1 / 3$ (Table 1). Note that a chance value of $1 / 3$ was conservative in that it ignored the possibility that Alex could have emitted any number of vocalizations besides "color," "shape," and "'matter." In all cases, the first single vocalization that Alex uttered was one of these category labels. Any other phrases he produced encoded requests for other objects or actions (e.g., "I want X'; see Pepperberg, 1987a, 1987b) and were not errors in identifications.

His score for just those pairs made of objects that were no longer novel (additional presentations of exemplars previously presented as novel) but that contained a color, shape, or material he could not label (e.g., plastic) was $13 / 17=76.5 \%$ for all trials $(p=.0003)$, and $10 / 13=$ $76.9 \%$ for first trials $(p=.0014)$.

\section{Transfer Tests with Novel Objects}

Alex's score was $96 / 113=85 \%$ on all trials, $79 / 96$ $=82.3 \%$ on first-trial performance $(p<.0001)$ with a chance value again of $1 / 3$ (Table 2). As mentioned above, these object pairs, in the order in which they were presented, and Alex's responses are listed in the Appendix. His scores for pairs containing one versus two totally novel objects (respectively, $86 \%$ and $83 \%$ for first trials, $p<.0001$ ) differed little. Based on the test for differences in proportions at the .05 confidence level, Alex's scores are not significantly better for questions involving novel exemplars versus familiar ones when the

Table 1

Alex's Responses to Queries of "What's same?" or "What's different?" to Pairs of Objects that were Similar but not Identical to Those Used in Training

\begin{tabular}{ccc}
\hline Question & $\begin{array}{c}\text { Correct Response } \\
\text { (\# times made) }\end{array}$ & $\begin{array}{c}\text { Incorrect Response } \\
\text { (\# times made) }\end{array}$ \\
\hline What's same? & $\begin{array}{c}\text { Color 16 } \\
\text { Shape 16 }\end{array}$ & $\begin{array}{c}\text { Shape 2; Matter 2 } \\
\text { Color 4; Matter 2 }\end{array}$ \\
& Matter 16 & Color 3; Shape 2 \\
What's different? & Color 17 & Shape 2; Matter 2 \\
& Shape 16 & Color 3; Matter 4 \\
& Matter 18 & Color 3; Shape 1 \\
\hline
\end{tabular}

Note-Statistics are reports in the text. 
Table 2

Alex's Responses to Queries of "What's same?" or "What's different?" to Pairs of Objects Significantly Different From Those Used in Training, Including Objects Made of Colors, Shapes, and Materials for Which He Might Not Have Labels

\begin{tabular}{ccl}
\hline Question & $\begin{array}{c}\text { Correct Response } \\
\text { (\# times made) }\end{array}$ & $\begin{array}{c}\text { Incorrect Response } \\
\text { (\# times made) }\end{array}$ \\
\hline What's same? & $\begin{array}{l}\text { Color 17 } \\
\text { Shape 16 }\end{array}$ & $\begin{array}{l}\text { Shape 1; Matter 2 } \\
\text { Color 3; Matter 1 }\end{array}$ \\
& Matter 17 & Color 3 \\
What's different? & Color 15 & Shape 1 \\
& Shape 16 & Color 1 \\
& Matter 15 & Color 3; Shape 2 \\
\hline
\end{tabular}

Note-Statistics are reported in the text.

results are examined for all trials, and are only just significantly better when the results are examined for firsttrial performance only. Usually, subjects perform less well on transfer tests, but the results here were not surprising. Remember that Alex received the objects themselves as his primary reward, and that there was therefore some inherent incentive to pay closer attention to both the objects and the response when these reward objects were new items that were potentially interesting to chew apart, to try to eat, or to use for preening.

\section{Probes}

The results of the probes demonstrate that Alex was indeed processing questions, as well as responding to the physical properties of the objects. The data are presented in Table 3; his scores were $55 / 61=90.2 \%$ on all trials $(p=.00001$, chance of $2 / 3)$ and $49 / 55=89.1 \%$ on firsttrial performance $(p<.0001)$.

\section{DISCUSSION}

The data indicate that at least one avian subject, an African Grey parrot, shows symbolic comprehension of the concept of same/different. The conditions of the tests, although not identical to those used by Premack (1976, 1983), were at least as rigorous as those used in his initial study with chimpanzees. Alex was presented the object pairs-including objects never before testedsimultaneously, rather than successively, so that, unlike animals that are trained on successive match (or oddity) to sample, he was unlikely to respond on the basis of "old" versus "new" or "familiar" versus "unfamiliar" (Premack, 1983, p. 127). Although Alex's task was one of symbolic comprehension of same and different (i.e., responding to questions of "What's same?" and "What's different?") as opposed to the production task most commonly employed with the language-trained chimpanzees (in which the animals responded with the labels "same" and "different"), Alex similarly had to respond symbolically on the basis of both (1) the instances of the categorical classes the objects represented and (2) the symbolic relationship (the labels "same" or "different") requested by the experimenter, and not on the basis of whether two items looked alike or were objects he had seen before. It is therefore unlikely that the task presented to Alex could be interpreted as a forced-choice conditional discrimination of the type generally used to determine nonhuman conceptual abilities.

Arguably, Alex did learn one form of conditional discrimination: He learned to respond to questions about two somewhat different objects phrased as "What's same?" and "What's different?" with categorical labels, whereas he maintained the ability to respond to questions about two identical objects phrased as "How many?" with the label "two X"' (Pepperberg, 1987a). However, comprehension and utilization of such a conditional constraint on the already inherently conditional nature of the productive labeling task (see Premack, 1976, pp. 140-142) more likely represent additional cognitive achievements (e.g., Premack, 1983, p. 129) rather than detract from the demonstrated abilities (see Pepperberg, 1983a).

Although the above findings present additional evidence of Alex's comprehension of concepts of categorical classes, determination of the extent of his abilities is still incomplete. For example, he has just begun to respond appropriately to questions of "What's the color of the metal key?" or "What shape is the green wood?" for collections of differently colored and shaped exemplars of various materials (see Essock, Gill, \& Rumbaugh, 1977; Granier-Deferre \& Kodratoff, 1986). And it is not yet clear if he can learn to respond directly to analogic "relations between relations"; for example, "Is the relation between $\mathrm{A} 1$ and $\mathrm{A} 2$ (sameldifferent) as that between $\mathrm{B} 1$ and B2?'" (Premack, 1983). However, it is clear that Alex has gone beyond match-to-sample or oddity-from-sample, is comprehending the vocal symbols "same" and "differ-

WHAT'S SAME?

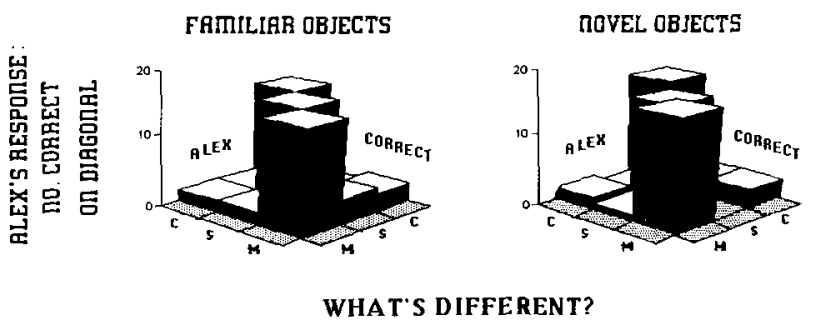

FRMILIAR DBJECTS

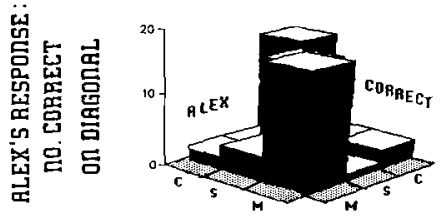

NDVEL OBJECTS

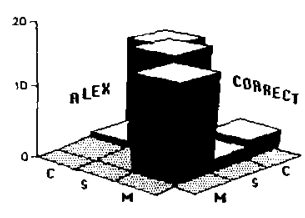

Figure 1. Histogram of results for questions of "What's same?" and "What's different?" for pairs of objects that employed objects that differed only slightly from training exemplars and for pairs that incorporated objects that differed significantly from training exemplars, including totally novel objects. The correct responses lie on the diagonal, the off-diagonal elements are the errors. $\mathrm{C}=$ color, $S=$ shape, $\mathbf{M}=$ matter. 
Table 3

Alex's Responses to Probes in Order to Learn if

He Was Responding on the Basis of the Experimenters' Questions, and Not Just on Physical Variations in the Objects

\begin{tabular}{ccc}
\hline Question & $\begin{array}{c}\text { Correct Response } \\
\text { (\# times made) }\end{array}$ & $\begin{array}{c}\text { Incorrect Response } \\
\text { (\# times made) }\end{array}$ \\
\hline What's same? & $\begin{array}{l}\text { Color 10 } \\
\text { Shape 11 } \\
\text { Matter 11 }\end{array}$ & $\begin{array}{c}\text { Matter 1 } \\
\text { Matter 2 }\end{array}$ \\
What's different? & $\begin{array}{l}\text { Color 8 } \\
\text { Shape 7 } \\
\text { Matter 8 }\end{array}$ & $\begin{array}{l}\text { Color 1 } \\
\text { Shape 2 }\end{array}$ \\
\hline
\end{tabular}

Note-Statistics are reported in the text.

ent," and is demonstrating a more abstract concept of category than he did in our previous study (Pepperberg, 1983a). His responses were not stimulus-specific; he performed as well on entirely novel objects as he did on familiar ones, including those for which he had no labels. Thus, he appeared to learn the task in terms of the concepts of "color," "shape," and "material."

It is not possible to determine whether Alex's demonstrated capabilities are the result of his extensive training on language-like tasks (e.g., labeling, categorical discrimination; note general discussions in Pepperberg \& Kozak, 1986, and Pepperberg, 1987a, on the relationship between cognitive abilities and training on language-like tasks). Reese (1972) has shown that, at least for children (grades $\mathrm{K}-2$ ), stating whether pairs of objects are "same" or "different" is a slightly easier task than labeling the individual objects. Reese's finding suggests that labeling is unlikely to be a prerequisite for determining same/different. Although some evidence exists that object discrimination is enhanced if different objects are associated either with differential responses (e.g., Reese, 1972) or with differential rewards (Brodigan \& Peterson, 1976; Peterson, 1984; Saunders \& Sailor, 1979; see discussion in Edwards et al., 1983), these studies generally involved a small number of exemplars and repeated presentation of these exemplars; in addition, the connections between the objects and the responses or rewards in these studies were not always referential. Remember, too, that Alex performed equally well for a wide variety of pairs of objects that were entirely novel, including ones whose colors, shapes, or materials could not be labeled. It is more likely that Alex's previous training merely provided him with experience in forming relationships (e.g., between exemplar and referent; see Marschark, 1983).

Alternatively, it is possible to view Alex's abilities on the same/different task as a measure of his communicative competence in what, for him, is an exceptional (i.e., nonspecies-specific) communication code (see Pepperberg, 1985,1986 ) - that is, as a measure of the degree to which the exceptional code (English vocalizations) has acquired functional significance. Communicative competence in birds is often judged by their ability to defend territory and mate successfully. In humans, communicative competence is often linked to cognitive abilities. Clearly, the standard avian index cannot be used to de- termine the communicative competence of a bird that has acquired some semblance of a human code. Rather, the bird must be tested in human terms. A valid index might be the degree of abstraction of the code in question-that is, not just whether the subject has learned to associate an object or its attributes with particular labels, but whether it has acquired some abstract concept of what these labels represent (Premack, 1983). Comprehension of the concepts of same and different and those of various categories provides evidence for some degree of communicative competence in the human code, although clearly one not nearly as complex as that attained by humans or even other language-trained species (Pepperberg, 1987a; Pepperberg \& Kozak, 1986).

Finally, although it is unlikely that these data will enable researchers to determine exactly where the Grey parrot may fit on any relative "intelligence scale" (e.g., Thomas, 1980), the above findings do suggest that symbolic comprehension of the concepts of same/different can no longer be considered the exclusive domain of primates.

\section{REFERENCES}

Bandura, A. (1971). Analysis of modeling procedures. In A. Bandura (Ed.), Psychological modeling (pp. 1-62). Chicago: Aldine-Atherton. Beecher, M. D., Stoddard, P. K., \& Loesche, P. (1985). Recognition of parents' voices by young cliff swallows. Auk, 102, 600-605.

Brodigan, D. L., \& Peterson, G. B. (1976). Two-choice conditional discrimination performance of pigeons as a function of reward expectancy, prechoice delay, and domesticity. Animal Learning \& Behavior, 4, 121-124.

Davis, H. (1984). Discrimination of the number three by a raccoon (Procyon lotor). Animal Learning \& Behavior, 12, 409-413.

Davis, H., \& BRADFord, S. A. (1986). Counting behavior in rats in a simulated natural environment. Ethology, 73, 265-280.

EDwards, C. A., JaGielo, J. A., \& Zentall, T. R. (1983). Same/different symbol use by pigeons. Animal Learning \& Behavior, 11, 349-355.

Essock, S. M., Grll, T. V., \& Rumbaugh, D. M. (1977). Language relevant object- and color-naming tasks. In D. M. Rumbaugh (Ed.), Language learning by a chimpanzee (pp. 193-206). New York: Academic Press.

FAlLs, J. B. (1985). Song matching in Western meadowlarks. Canadian Journal of Zoology, 63, 2520-2524.

FALLS, J. B., KReBS, J. R., \& MCGRegor, P. K. (1982). Song match ing in the great tit (Parus major): The effect of similarity and familiarity. Animal Behavior, 30, 997-1009.

GraniER-DEFERRE, C., \& KoDRATOFF, Y. (1986). Iterative and recursive behaviors in chimpanzees during problem solving: A new descriptive model inspired from the artificial intelligence approach. Cahiers de Psychologie Cognitive, 6, 483-500.

HerRnstein, R. J. (1984). Objects, categories, and discriminative stimuli. In H. L. Roitblat, T. G. Bever, \& H. S. Terrace (Eds.), Animal cognition (pp. 233-261). Hillsdale, NJ: Erlbaum.

Hulse, S. H., \& CrNX, J. (1985). Relative pitch perception is constrained by absolute pitch in songbirds (Mimus, Molothrus, and Sturnus). Journal of Comparative Psychology, 99, 176-196.

KAMIL, A. C. (1984). Adaptation and cognition: Knowing what comes naturally. In H. L. Roitblat, T. G. Bever, \& H. S. Terrace (Eds.), Animal cognition (pp. 533-544). Hillsdale, NJ: Erlbaum.

KROODSMA, D. E. (1979). Vocal dueling among male marsh wrens: Evidence for ritualized expressions of dominance/subordinance. Auk, 96, 506-515.

MacPhaIL, E. M. (1985). Vertebrate intelligence: The null hypothesis. Philosophical Transactions of the Royal Society, Series B, 308, 37-51. 
Marschark, M. (1983). A code by any other name .... Behavioral \& Brain Sciences, 6, 151-152.

MCCluRE, M. K., \& Helland, J. (1979). A chimpanzee's use of dimensions in responding same and different. Psychological Record, 29, 371-378.

Menzel, E. W., JR., \& Juno, C. (1982). Marmosets (Saguinus fuscicollis): Are learning sets learned? Science, 217, 750-752.

MENZEL, E. W., JR., \& JUNO, C. (1985). Social foraging in marmoset monkeys and the question of intelligence. Philosophical Transactions of the Royal Society, Series B, 308, 145-158.

Michael, J., Whitely, P., \& Hesse, B. (1983). The pigeon parlance project. VB News, 2, 6-9.

Moran, G., Joch, E., Sorenson, L. (1983, June). The response of meerkats (Suricata suricatta) to changes in olfactory cues on established scent posts. Paper presented at the annual meeting of the Animal Behavior Society, Lewisburg, PA.

Mowrer, O. H. (1960). Leaming theory and symbolic processes. New York: Wiley.

Park, T. J., \& Dooling, R. J. (1985). Perception of species-specific contact calls by budgerigars (Melopsitzacus undulatus). Journal of Comparative Psychology, 99, 391-402.

Pepperberg, 1. M. (1979, June). Functional word use in an African Grey parrot. Paper presented at the annual meeting of the Animal Behavior Society, New Orleans, LA.

PePperberG, I. M. (1981). Functional vocalizations by an African Grey parrot (Psittacus erithacus). Zeitschrift für Tierpsychologie, 55, 139-160.

Pepperberg, I. M. (1983a). Cognition in the African Grey parrot: Preliminary evidence for auditory/vocal comprehension of the class concept. Animal Leaming \& Behavior, 11, 179-185.

PepPerberg, I. M. (1983b, June). Interspecies communication: Innovative vocalizations of an African Grey parrot. Paper presented at the annual meeting of the Animal Behavior Society, Lewisburg, PA.

PePperberG, I. M. (1985). Social modeling theory: A possible framework for understanding avian vocal learning. Auk, 102, 854-864.

Pepperberg, I. M. (1986). Acquisition of anomalous communicatory systems: Implications for studies on interspecies communication. In R. J. Schusterman, J. A. Thomas, \& F. G. Wood (Eds.), Dolphin cognition and behavior: A comparative approach (pp. 289-302). Hillsdale, NJ: Erlbaum.

Pepperberg, I. M. (1987a). Evidence for conceptual quantitative abilities in the African Grey parrot: Labeling of cardinal sets. Ethology, 75, 37-61.

Pepperberg, I. M. (1987b). Interspecies communication: A tool for assessing conceptual abilities in the African Grey parrot (Psittacus erithacus). In G. Greenberg \& E. Tobach (Eds.), Language, cognition and consciousness: Integrative levels (pp. 31-56). Hillsdale, NJ: Erlbaum.

Pepperberg, I. M. (in press). An interactive modeling technique for acquisition of communication skills: Separation of 'labeling' and 'requesting' in a psittacine subject. Applied Psycholinguistics.

PePperberG, I. M., KozaK, F. A. (1986). Object permanence in the African Grey parrot (Psittacus erithacus). Animal Learning \& Behavior, 14, 322-330.

Peterson, G. B. (1984). How expectancies guide behavior. In H. L. Roitblat, T. G. Bever, \& H. S. Terrace (Eds.), Animal cognition (pp. 135-148). Hillsdale, NJ: Erlbaum.

Premack, D. (1976). Intelligence in ape and man. Hillsdale, $\mathrm{NJ}$ : Erlbaum.

Premack, D. (1978). On the abstractness of human concepts: Why it would be difficult to talk to a pigeon. In S. H. Hulse, H. Fowler, \& W. K. Honig (Eds.), Cognitive processes in animal behavior (pp. 423-451). Hillsdale NJ: Erlbaum.

Premack, D. (1983). The codes of man and beasts. Behavioral \& Brain Sciences, 6, 125-167.

Putney, R. T. (1985). Do willful apes know what they are aiming at? Psychological Record, 35, 49-62.

REESE, H. W. (1972). Acquired distinctiveness and equivalence of cues in young children. Journal of Experimental Child Psychology, 13, 171-182.
Rumbaugh, D. M., \& PATe, J. L. (1984). Primates' leaming by levels. In G. Greenberg \& E. Tobach (Eds.), Behavioral evolution and integrative levels (pp. 221-240). Hillsdale, NJ: Erlbaum.

Santiago, H. C., \& Wright, A. A. (1984). Pigeon memory: Same/different concept learning, serial probe recognition acquisition, and probe delay effects on the serial-position function. Journal of $E x-$ perimental Psychology: Animal Behavior Processes, 10, 498-512.

SAunders, R., \& SAILOR, W. (1979). A comparison of the strategies of reinforcement in two-choice learning problems with severely retarded children. American Association for the Education of the Severely (Profoundly) Handicapped Review, 4, 323-334.

Savage-Rumbaugh, E. S., Sevcik, R. A., Rumbaugh, D. M., \& RUBERT, E. (1985). The capacity of animals to acquire language: Do species differences have anything to say to us? Philosophical Transactions of the Royal Society, Series B, 308, 177-185.

Shy, E., MCGregor, P. K., \& KREBS, J. (1986). Discrimination of song types by male great tits. Behavioural Processes, 13, 1-12.

Thомas, R. K. (1980). Evolution of intelligence: An approach to its assessment. Brain, Behavior \& Evolution, 17, 454-472.

TODT, D. (1975). Social learning of vocal patterns and modes of their applications in Grey parrots. Zeitschrift für Tierpsychologie, 39, 178-188.

Wright, A. A., Santiago, H. C., \& Sands, S. F. (1984). Monkey memory: Same/different concept learning, serial probe acquisition, and probe delay effects. Journal of Experimental Psychology: Animal Learning Processes, 10, 513-529.

Wright, A. A., Santiago, H. C., URcuioli, P. J., \& Sands, S. F. (1984). Monkey and pigeon acquisition of same/different concept using pictorial stimuli. In M. L. Commons, R. J. Herrnstein, \& A. R. Wagner (Eds.), Quantitative analysis of behavior (Vol. 4, pp. 295317). Cambridge, MA: Ballinger.

Zentall, T. R., EDwards, C. A., Moore, B. S., \& Hogan, D. E. (1981). Identity: The basis for both matching and oddity learning in pigeons. Journal of Experimental Psychology: Animal Behavior Processes, 7, 70-86.

Zentall, T. R., Hogan, D. E. (1974). Abstract concept learning in the pigeon. Journal of Experimental Psychology, 102, 393-398.

Zentall, T. R., Hogan, D. E., \& Edwards, C. A. (1984). Cognitive factors in conditional learning by pigeons. In H. L. Roitblat, T. G. Bever, \& H. S. Terrace (Eds.), Animal cognition (pp. 389-405). Hillsdale, NJ: Erlbaum.

\section{NOTES}

1. There were approximately 70 different objects (food items were rarely used), three possible correct responses, and two different questions for the same/different task alone. For example, if we asked "What's same?" desired the response to be "color," and chose a round green key as one of the exemplars, this key could be paired with 2-, 3-, 4-, 5-, or 6-cornered objects of paper, wood, or rawhide, 3-, 4-, or 6comered objects of plastic, plus objects such as green clothespins, wooden or plastic cubes or spheres, plastic boxes and cups, and so forth. A similar set of permutations existed for responses of "shape," "matter," and the question "What's different?" In addition, Alex was concurrently being tested on numerical concepts ("How many?') and additional labels ("What's this?" "What color," etc.).

2. Alex had acquired these vocalizations incidentally from their use by trainers in a different study (Pepperberg, 1983a). Whether he was producing the phrases "What color?" and "What shape?" intentionally as requests for information was unclear (Pepperberg, 1983b). However, all trainers were instructed to respond as if these were intentional requests, and to provide the color or shape of the object in question. Alex acquired the color labels "orange" and "gray" in this manner by querying us as to the previously unlabeled colors of, respectively, a carrot and his reflection (Pepperberg, 1983a, 1983b).

3. That is, it is possible that a vocalization could be recognized auditorily as a label by all trainers (interobserver agreement $>90 \%$ ) before Alex comprehends the connection between this object label and its referent. His comprehension, therefore, could be poor at the onset of testing; however, label production has preceded label comprehension 
for only those cases in which we have given Alex a novel object to correspond to a novel vocalization he has spontaneously produced (e.g., seed corn for "rock corn"; Pepperberg, 1983b).

4. At the beginning of the project, each exemplar was assigned a number and the test order was determined by a random-number table. When the number of exemplars exceeded 10 , a trainer not involved in testing picked the exemplars out of the toy box and wrote down the order of her choice. In the present study and in that of numerical concepts (Pepperberg, 1987a), the test groups were listed on a page, the list itself was covered, and a trainer other than the examiner randomly ordered the list.

5. It was occasionally the examiner who stood corrected: In about 1 in 20 trials (particularly during student exam periods), an examiner would err and scold Alex for a correct response. Alex would repeat his correct response, despite our procedures, which encouraged a loseshift strategy. The examiner would then recognize her error, and the bird would get his reward. Note that although this is not a formal blind test, it produced the same results. Too, other forms of blind tests have been performed: Alex has several idiosyncratic labels for objects ("banerry" for apple, "truck" for toy metallic cars, "rock corn'" for dried corn, "wheat" for cereal, "cork nut" for almond). People unfamiliar with Alex and with these labels have queried him on these objects; he was correct on $4 / 5$ first trials.

6. Some of these items were previously used as novel objects in a study on recognition of quantity (Pepperberg, 1987a); in those trials, Alex was required only to produce the numerical label representing quantity, not the label of the object. Although labels for these particular objects were not trained, Alex would occasionally learn their labels from students' replies to his queries of "What's that?"

\section{APPENDIX}

\section{Concepts of Same/Different}

Trials involving first presentation of objects that were never part of sameldifferent training or that were entirely novel:

\begin{tabular}{|c|c|c|c|c|c|}
\hline \multirow[b]{2}{*}{ Pair* } & \multicolumn{2}{|c|}{ Question } & \multicolumn{3}{|c|}{ Responses } \\
\hline & Different & Same & $\overline{\mathrm{C}}$ & $\mathrm{s}$ & $\bar{M}$ \\
\hline $5 \mathrm{CWhP}-3 \mathrm{CWhP}$ & $\bar{x}$ & & & 1 & \\
\hline $4 \mathrm{CRK}-4 \mathrm{CBrK}$ & $\mathrm{x}$ & & 1 & & \\
\hline 4CPPK-3CRK & & $x$ & & & \\
\hline 4CRK-4CBrW & & $\mathrm{x}$ & & 1 & \\
\hline 4CRK-4CGK & $\mathbf{x}$ & & 1 & & \\
\hline 4CGP- $\partial \mathrm{GK}$ & & $\mathrm{x}$ & 1 & & \\
\hline$\partial \mathrm{OK}-4 \mathrm{COK}$ & $\mathrm{x}$ & & & 1 & \\
\hline$\partial \mathrm{RH}-\partial \mathrm{BK}$ & & $\mathbf{x}$ & & 1 & \\
\hline 2COH-3CGyH & & $\mathrm{x}$ & 1 & & 2 \\
\hline $4 \mathrm{CBK}-\partial \mathrm{BK}$ & $\mathrm{x}$ & & & 1 & \\
\hline 5 CGW- $\partial \mathrm{GK}$ & & $\mathrm{x}$ & 2 & 1 & \\
\hline JRK-3CRK & $\mathrm{x}$ & & & $i$ & \\
\hline$\partial \mathrm{BrK}-4 \mathrm{CBrP}$ & & $\mathrm{X}$ & 2 & & \\
\hline 4CYP-4CYW & $\mathrm{x}$ & & & & \\
\hline $3 \mathrm{COP}-4 \mathrm{CBP}$ & & $\mathrm{x}$ & & & 1 \\
\hline 3CGP-3COW & & $\mathrm{x}$ & & 1 & \\
\hline 4CGyW-4CGyP & $\mathrm{x}$ & & & & 1 \\
\hline $3 \mathrm{CPpK}-4 \mathrm{CPpK}$ & $\mathrm{x}$ & & & 1 & \\
\hline$\partial \mathrm{RH}-4 \mathrm{CYH}$ & & $\mathrm{X}$ & & & 1 \\
\hline 4CPkP-4CPpW & & $\mathrm{X}$ & & 1 & \\
\hline SCOW-4COP & & $\mathrm{x}$ & 1 & & \\
\hline 4CGyP-2CGyW & & $\mathrm{x}$ & 1 & & \\
\hline$\partial \mathrm{OPls}-4 \mathrm{COH}$ & & $\mathbf{x}$ & 1 & & \\
\hline 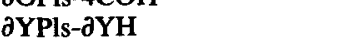 & $\mathbf{x}$ & & & 1 & 2 \\
\hline YPIsCup-4CYH & & $\mathrm{x}$ & 1 & & \\
\hline 4CGPIsK-4CRK & & $\mathrm{x}$ & & 1 & \\
\hline YWoolen Ball-YWdn Bead & $\mathrm{x}$ & & & & 1 \\
\hline BMtl Truck- $\partial \mathbf{B K}$ & $\mathrm{X}$ & & & 1 & \\
\hline GyHairclip-3CRK & $\mathbf{x}$ & & & & 1 \\
\hline
\end{tabular}

\begin{tabular}{|c|c|c|c|c|c|}
\hline \multirow[b]{2}{*}{ Pair* } & \multicolumn{2}{|c|}{ Question } & \multicolumn{3}{|c|}{ Responses } \\
\hline & Different & Same & $\overline{\mathrm{C}}$ & $\mathrm{s}$ & $\mathbf{M}$ \\
\hline$\partial B P l s K-\partial B K$ (dif sz) & $\mathbf{x}$ & & & 1 & 2 \\
\hline$\partial$ PpPls ring- $\partial \mathrm{BK}$ & & $\mathbf{X}$ & & 1 & \\
\hline 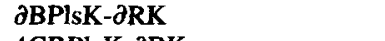 & & $\boldsymbol{X}$ & & 1 & \\
\hline 4CRPIsK-дRK & & $\mathbf{x}$ & 1 & & \\
\hline $\begin{array}{l}\text { 4CBPIsK-4CBK } \\
\text { 3CGyP-4CGyW }\end{array}$ & $\mathrm{X}$ & $x$ & 1 & & \\
\hline 4CYPlsK-3CPlsK & $\mathrm{x}$ & & 1 & 2 & \\
\hline 3CGP-5CBP & & $\mathbf{X}$ & 1 & & \\
\hline 4CGP-3CPkP & & $\mathbf{X}$ & & & \\
\hline 6CRPls-6CBW & & $\begin{array}{l}x \\
x\end{array}$ & 1 & 2 & \\
\hline $\begin{array}{l}\text { aBPlsK-4CGPIsK } \\
\text { 4CGPlsBox-dGPIsK }\end{array}$ & $\mathrm{X}$ & $\mathrm{X}$ & & 1 & \\
\hline RWoolen Ball- $\partial \mathrm{GyK}$ & & $x$ & & 1 & \\
\hline GyWoolen Ball-2GyP & $\mathrm{x}$ & & 1 & & 2 \\
\hline 4CBPIsK-2GPIsK & & $\mathrm{X}$ & & & \\
\hline 4CGPlay-Doh-dGPls & & $\mathrm{x}$ & 1 & & \\
\hline $\begin{array}{l}\text { YWoolen Ball-PkWoolenBall } \\
\text { PegWood- } \partial O W d n B e a d\end{array}$ & $\mathrm{X}$ & $\mathrm{x}$ & & & \\
\hline MtiCup-3CRK & & $\mathrm{x}$ & & & \\
\hline Grate-3COK & & $\mathrm{x}$ & & & \\
\hline CurtainHook-дGyK & $\mathrm{x}$ & & & 1 & \\
\hline dYPls-Washer & & $\mathrm{x}$ & & 1 & \\
\hline Mostaciolli-Shell & $\mathrm{X}$ & & & 1 & \\
\hline วBPIsK-DiamondBPIsK & $\mathrm{X}$ & & & 1 & \\
\hline 4CPkPlay-Doh-4CPpPlay-Doh & $\mathrm{x}$ & & 2 & 1 & \\
\hline YmtlTruck-3CPpK & & $\mathrm{x}$ & & & 1 \\
\hline 3CPkP-HeartPk Candy & & $\mathrm{X}$ & 1 & & \\
\hline $\begin{array}{l}\text { 4CPpP-4CGP } \\
\text { 6CRPls-6COH }\end{array}$ & $\mathrm{x}$ & $\mathrm{X}$ & 1 & 1 & \\
\hline 3CBPls-3CBW & $\mathrm{x}$ & & 1 & & 2 \\
\hline RWdnBead-PpWdnBead & $\mathrm{x}$ & & 1 & & \\
\hline RWdnBead-WhWdnCube & & $\mathbf{X}$ & & & \\
\hline 5CRH-5CRPlay-Doh & $\mathrm{X}$ & & & & l \\
\hline WhCstPlay-Doh-4CWhP & & $\mathrm{X}$ & 1 & & \\
\hline BCstClay-BCstP & $\mathbf{X}$ & & & & \\
\hline Banerry-4CRK & & $\mathbf{x}$ & 2 & & 1 \\
\hline $\begin{array}{l}\text { RWdnCube-GWdnCube } \\
\text { dOK-2COPIsBead }\end{array}$ & $\mathrm{X}$ & $\mathrm{x}$ & 1 & & \\
\hline 3CPkPlay-Doh-4CPkPlay-Doh & $\mathrm{x}$ & & & 1 & \\
\hline GyWdnCube-GyWoolen Ball & & $\mathbf{X}$ & 1 & & \\
\hline BPIsBox-5CBPlay-Doh & & $\mathbf{x}$ & 1 & & \\
\hline 6CRPIs-4CRPIsK & $\mathrm{x}$ & & & 1 & \\
\hline $\begin{array}{l}\text { OMtlBox-BPlsBox } \\
\text { PpCube-PpдBead }\end{array}$ & $\mathrm{X}$ & $\mathbf{X}$ & 1 & $\begin{array}{l}2 \\
1\end{array}$ & \\
\hline GyPlsPen-YWdnPencil & & $\mathrm{x}$ & & 1 & \\
\hline GMtlCar-GWdnCube & & $\mathbf{x}$ & 1 & & \\
\hline GSpool-BrSpool & $\mathbf{X}$ & & 1 & & \\
\hline RPIsHeart-RPIsRing & $\mathbf{X}$ & & & 1 & \\
\hline Penny-Dime & $\mathbf{x}$ & & 1 & & \\
\hline Die-GWdnCube & & $\mathrm{x}$ & 1 & 2 & \\
\hline GChalk-WhChalk & $\mathbf{X}$ & & 1 & & \\
\hline RPIsCu & & $\mathrm{x}$ & & & 1 \\
\hline GyMtlBox-GyWdnCube & $\mathbf{X}$ & & & & 1 \\
\hline Pk paperclip-B paperclip & $\mathbf{x}$ & & 1 & & \\
\hline $4 \mathrm{CBr} P-4 \mathrm{Cl}$ & $\mathbf{X}$ & & & & 1 \\
\hline 4CYClay-4CYPlay-Doh & $\mathbf{x}$ & & 1 & & 2 \\
\hline G Tape-Y Tape & $\mathbf{X}$ & & 1 & & \\
\hline BrPlsCube-BrWdnCube & $\mathbf{X}$ & & & & 2 \\
\hline $\begin{array}{l}\text { YPls Box-BPls screw } \\
\text { B eraser-Y eraser }\end{array}$ & $\mathbf{X}$ & $X$ & $\begin{array}{l}1 \\
1\end{array}$ & & \\
\hline Y Bead-Grape & & $\mathrm{x}$ & & 2 & 1 \\
\hline Gy leather shoe-glove & $x$ & & & 1 & \\
\hline Pk metal needle-Y pencil & & $\mathbf{X}$ & & 1 & \\
\hline RPls ring-Ypls tube & & $\mathbf{X}$ & & & 1 \\
\hline RMH spangle-BMH spangle & $\mathrm{X}$ & & 1 & & \\
\hline almond-2CGW & $\mathbf{X}$ & & 1 & & \\
\hline GPlsBead-GWdBead & $\mathrm{x}$ & & & & \\
\hline
\end{tabular}


Note-Each object of each pair varied from the training exemplars in one or more dimensions (training objects were red, green, blue; triangular or square; wood or rawhide) and many objects (e.g., those that were not standard polygons, those made of plastic, wool, clay, or PlayDoh) had never been seen by the subject except on a shelf in the lab for a short period prior to testing. In all cases, Alex's response of color, shape, or matter was the first single word uttered. Entire phrases that encoded requests for other objects or actions (e.g., "I want X") were not counted, because we had evidence that such utterances were legitimate requests and not incorrect identifications (Pepperberg, in press). Alex was correct on $96 / 113=85 \%$ on all trials and $79 / 96=82.3 \%$ on first trials $(p<.0001)$ with chance value of $1 / 3$. This value for chance is conservative, in that it ignores the possibility that Alex could have produced many different erroneous vocalizations (e.g., labels for colors, shapes, materials, numerical quantities).

*Codes: $\mathrm{R}=$ rose, $\mathrm{G}=$ green, $\mathrm{Y}=$ yellow, $\mathrm{O}=$ orange, $\mathrm{B}=$ blue, Gy $=$ gray, $\mathrm{Pp}=$ purple, $\mathrm{Pk}=$ pink, $\mathrm{Wh}=$ white, $\mathrm{Br}=$ Brown, $\mathrm{C}$ $=$ corner, $\partial=$ round, $P l s=$ plastic, $\mathbf{H}=$ rawhide, $\mathbf{W}=$ wood, $K=$ key, $\mathbf{P}=$ paper, $\mathrm{Mtl}=$ metal, $\mathrm{Cst}=$ crescent.

†Numbers give the order in which Alex produced the category label ( $\mathrm{C}=$ color, $\mathrm{S}=$ shape, $\mathrm{M}=$ matter $)$ : " 1 " designates which category label was his first response, " 2 " his second when his first was incorrect.

(Manuscript received January 29, 1987; revision accepted for publication June 3,1987 .)

\section{NOTICE}

\section{SPECIAL ISSUE \\ PSYCHOBIOLOGY \\ CALL FOR MANUSCRIPTS}

A special issue of Psychobiology is being planned in the area of Psychobiology of Sexual Differentiation and Gender-Related Behaviors. It will include both empirical research and review papers. Manuscripts should review empirical literatures, advance theory or present major sets of data. Publication of the special issue is planned for Fall 1988. The deadline for initial submissions is March 1, 1988.

Contributions intended for the special issue should be sent to the guest editor: Jane Stewart, Center for Studies in Behavioral Neurobiology, Concordia University, 1455 de Maisonneuve Blvd. West, Montreal, PQ H3G 1M8, Canada. 